\title{
A Novel Compact ACS-fed UWB antenna with Resonators for WiMax/WLAN Applications
}

\author{
Yifan Wang, Long $\operatorname{Jin}^{1}$ \\ ${ }^{1}$ University of Electronic Science and Technology of China, Chengdu 611731, China;
}

Keywords: Asymmetric coplanar strip (ACS)-fed, WLAN/WiMAX, ultrawideband antenna, SRR, U-shaped slot.

\begin{abstract}
The design of a very compact asymmetric coplanar strip (ACS) feed printed antenna with resonators for WiMax/WLAN applications is presented. The antenna is simply formed by a U-shaped slot embedded at the center of the asymmetric coplanar strip, rectangular split-ring resonator (SRR) embedded on the radiating patch and the asymmetric ground plane. The proposed antenna with a total size of $26.1 \times 8.5 \mathrm{~mm}^{2}$ has been constructed and tested. The impendence bandwidth with $10 \mathrm{~dB}$ return loss is from 3.1 to $10.6 \mathrm{GHz}$ with two rejected bands which cover 3.3-4 and 5-6 GHz.
\end{abstract}

\section{Introduction}

After the Federal Communications Commission allocated 3.1-10.6 GHz for UWB systems ${ }^{[1]}$,such as imaging system, radars, sensor networks and wireless personal area networks, different types of designs catering to various requirements and applications have been reported ${ }^{[2-4]}$. To reduce the size of compact antennas developed with CPW feed techniques; in past few years, asymmetric coplanar strip fed antenna has been introduced for some held devices. Some ACS-fed antenna with a very compact size of $20 \times 10 \mathrm{~mm} 2$ has been proposed ${ }^{[3]}$. The other important issue of UWB systems is possible electromagnetic interference with other devices working in universal frequency band, such as WLAN (5.15-5.85 GHz) or WiMAX (3.3-3.7 GHz). Rejecting certain sub-bands of the UWB range can avoid interference needs ${ }^{[5]}$. Some dual or multi-rejected band UWB antennas have been presented ${ }^{[6.7]}$, but the size of those antennas mentioned above mostly is large for some platform.

In this Letter, the design of a small ACS-fed UWB antenna with two rejected bands is presented. By using the ACS-fed structure, the proposed antenna is nearly half the size of the coplanar waveguide-fed antennas. One rectangular SRR are etched on the radiating patch and a U-shaped slot are embedded at the center of the asymmetric coplanar strip, and the proposed antenna not only covers the whole UWB operating bands, but also is simple and miniature. The antenna has a compact size of $26.1 \times 8.5 \times 1.6 \mathrm{~mm}^{3}$, and the dimensions are much more compact compared with the UWB antennas presented in ${ }^{[8.9]}$.

\section{Antenna design:}

Fig. 1 shows the configuration and photograph of the proposed antenna, which is printed on a $1.6 \mathrm{~mm}$-thick FR4 substrate with a relative permittivity of 4.4 and a loss tangent of 0.02 . The proposed antenna consists of a $50 \Omega$ ACS feedline with a U-shaped slot, a lateral ground plane and a right-angled trapezoidal radiating patch etched with one rectangular SRR. The ACS feedline, with a signal strip width of $2.8 \mathrm{~mm}$ and a gap distance of $0.28 \mathrm{~mm}$, is between the signal strip and the asymmetric ground plane. 


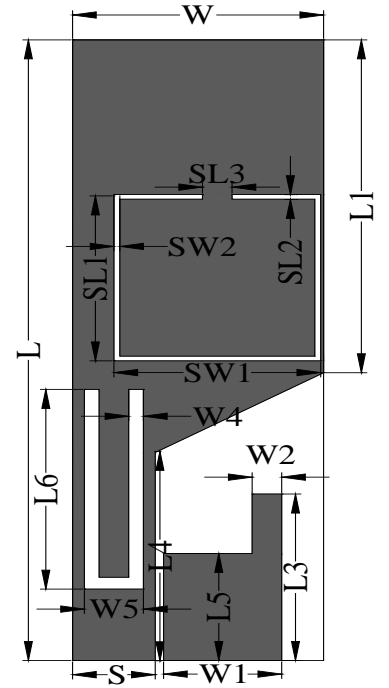

a

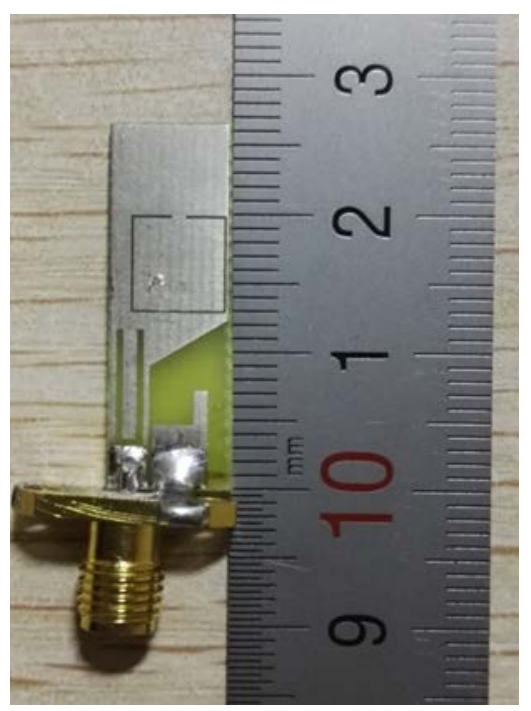

b

Fig.1 Configuration and photograph of proposed antenna a Configuration b Photograph

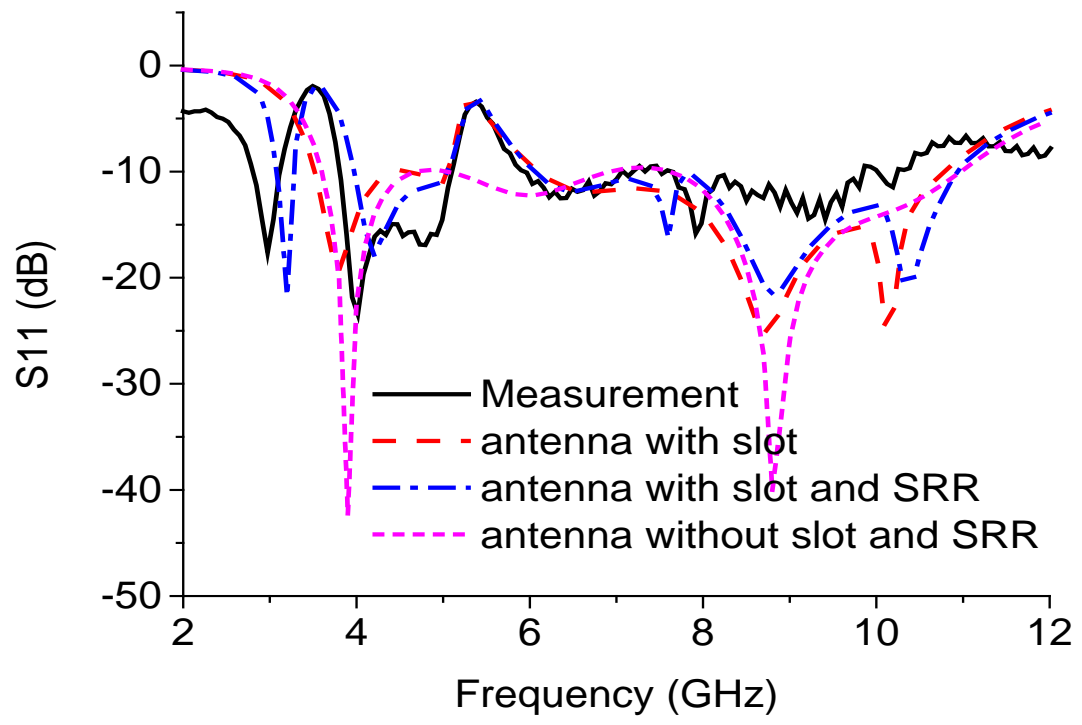

Fig2. Simulated and measured return losses of various antennas involved

The effect of the slot and SRR etched on the feedline and the radiating patch was investigated through simulation. As shown in Fig.2; the simulated -10dB impendence bandwidth of antenna without slot and SRR is $10 \mathrm{GHz}(3.6-10.6 \mathrm{GHz})$, which cannot cover the UWB band totally. Then a U-shaped slot is embedded in the ACS feedline to generate the resonant band at about 5.4GHz. The overall length (L6 + L6 + W5) of the slot is set to be about $1 / 4 \lambda$ at the resonant frequency $(5.4 \mathrm{GHz}$ in this design) of the antenna. Another notched band is at $3.6 \mathrm{GHz}$ by introducing SRR to remove the undesired 3.6GHz WiMax (3.3-3.7 GHz), while the length of SRR is set to be about $1 / 4 \lambda$ at the rejected frequency (about 3.6GHz). An ultra-wide impedance matching from 3.1 to $10.6 \mathrm{GHz}$ can be achieved through properly adjusting the dimensions of the antenna. The prototype of the proposed antenna was simulated by Ansoft HFSS 15.0. The optimized design parameters and values are as follows: $\mathrm{W}=8.5 \mathrm{~mm}$; $\mathrm{W} 1=4 \mathrm{~mm}$; W2 = $1 \mathrm{~mm}$; W3 = $2 \mathrm{~mm}$; W4 = $0.5 \mathrm{~mm}$; $\mathrm{L}=26.1 \mathrm{~mm}$; L1 = 14 $\mathrm{mm}$; L2 = $3 \mathrm{~mm} ; \mathrm{L} 3=7 \mathrm{~mm} ; \mathrm{L} 4=8.7 \mathrm{~mm}$; L5 = $8.5 \mathrm{~mm} ; \mathrm{S}=2.8 \mathrm{~mm} ; \mathrm{SL} 1=7 \mathrm{~mm} ; \mathrm{SL} 2=0.5 \mathrm{~mm}$; $\mathrm{SL3}=1 \mathrm{~mm} ; \mathrm{SW} 1=7 \mathrm{~mm} ; \mathrm{SW} 2=0.5 \mathrm{~mm}$. 


\section{Results and discussion:}

The proposed antenna has been fabricated and measured, and its photograph is shown in Fig.1. The simulated and measured return losses of this antenna are given in Fig.2. From this Figure, it can be observed that the measured results are in agreement with the simulated values. The differences between the measured and simulated results at $10-10.6 \mathrm{GHz}$ are probably owing to fabrication and test errors. The input impedance bandwidth of the proposed antenna is from 3.1 to $10.6 \mathrm{GHz}$, in which there are two rejected bands which cover the 3.3-4 GHz band and the 5.0-6.0 GHz band.
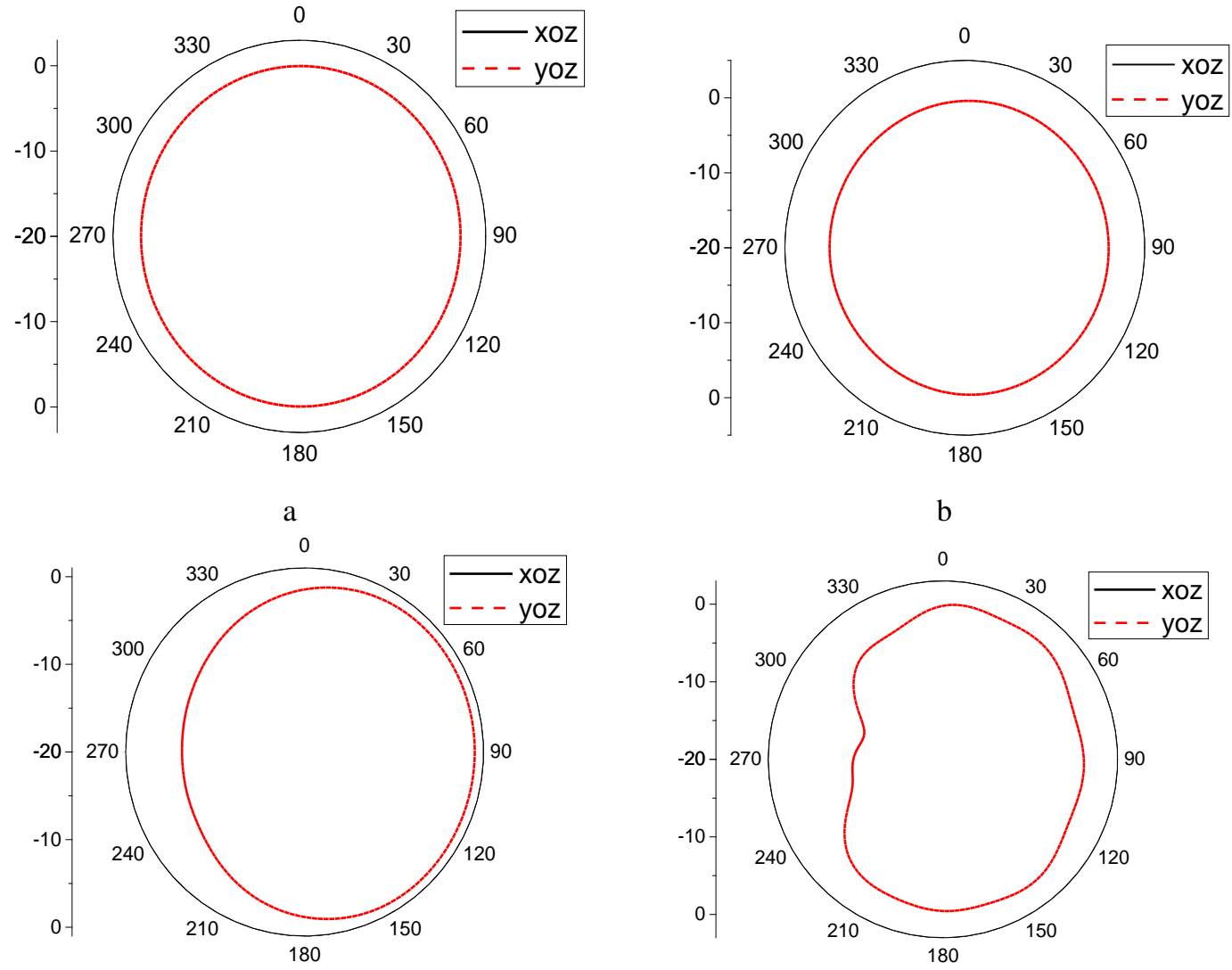

C

$\mathrm{d}$

Fig.3 Simulated normalized radiation patterns of proposed antenna at 3.2, 4.5, 7.5 and $10 \mathrm{GHz}$ a $3.2 \mathrm{GHz}$ b $4.5 \mathrm{GHz}$ c $7.5 \mathrm{GHz}$ d $10 \mathrm{GHz}$

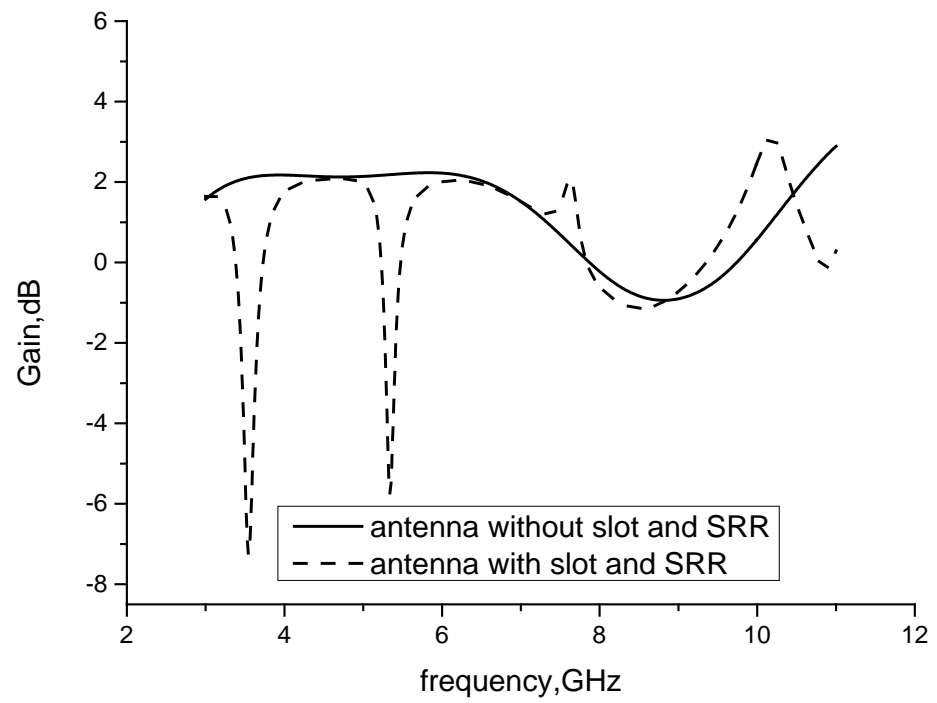

Fig.4 Simulated gain of antenna 
Fig.3 shows simulated far-field radiation patterns in the H-plane (yoz-plane) and E-plane (xoz-plane) at 3.2, 4.5, 7.5 and $10 \mathrm{GHz}$ respectively. As shown in the Figure, the antenna exhibits nearly omnidirectional H-plane (yoz-plane) and bidirectional E-plane (xoz-plane) patterns. From the $\mathrm{H}$-plane patterns, it can be seen that the radiation pattern deteriorates slightly at the higher resonant frequency, and this may be due to the fact that the asymmetric ground plane of the ACS-fed structure is half of the CPW-fed antenna. The peak gains of the antenna without U-shaped slot and SRR are compared with the proposed antenna. As shown in the Fig 4, the average gains of 1.45, 2.21 and $1 \mathrm{dBi}$ are obtained for the $3.1-3.3 \mathrm{GHz}, 4.0-5.0 \mathrm{GHz}$ and $6.0-10.6 \mathrm{GHz}$. It can be observed that the peak gains of the proposed antenna are in good agreement with the antenna without slot and SRR except for two rejected bands which cover 3.3-4 GHz and 5.0-6.0 GHz.

\section{Conclusion}

A compact ACS-fed UWB monopole antenna with U-shaped slot and a rectangular SRR has been proposed, manufactured and measured. The proposed antenna has a simple structure and a very compact size of $26.1 \times 8.5 \times 1.6 \mathrm{~mm} 3$. The simulated and measured results show the proposed antenna can avoid inferences with the systems working in WiMAX and WLAN band for wireless communication, while keeping a good input impedance in the other UWB band. The simulated and measured results show that the antenna can achieve nearly omnidirectional radiation characteristics and stable gains. The results indicate that the proposed antenna could be a promising candidate for various wireless communication systems.

\section{References}

[1]. Federal Communications Commission: 'First report and order'. Revision of part 15 of the Commission's rules regarding ultra-wideband transmission systems, February 2002

[2]. R. Azim, M. T. Islam and N. Misran: "Compact tapered-shape slot antenna for UWB applications”. IEEE Antennas Wireless Prop. Lett. vol. 10(2011), pp. 1190-1193.

[3]. Gao. G.P., Hu, B., and Zhang, J.S.: 'Design of a miniaturization printed circular-slot UWB antenna by the half-cutting method'. IEEE Antennas Wireless. Prop. Lett. Vol. 12(2013), pp. 567-570.

[4]. Deepu. V., Raj, R.K., Joseph, M., Suma, M.N., and Mohanan, P. :‘Compact asymmetric coplanar strip fed monopole antenna for multiband applications'. IEEE Trans. Antennas Propag. Vol.55(2007) NO.8, pp. 2351-2357

[5]. D. Sarkar, K.V. Srivastava, and K. Saurav, “A compact microstrip-fed triple band-notched UWB monopole antenna,” IEEE Antennas Wireless Prop. Lett. Vol. 13 (2014) pp. 396-399.

[6]. M., Shirzad, H., Movagharnia, S., et al.: 'Planar monopole antenna with dual interference suppression functionality’, IEEE Microw. Wireless. Compo. Lett. Vol.12 (2013), pp. 1554-1557.

[7]. Wang.J, Yin, Y.Z., Liu, X.L., et al.: 'Trapezoid UWB antenna with dual band-notched characteristics for WiMAX/WLAN bands’, Electron. Lett. , Vol.49 (2013) No. 11, pp. 685-686.

[8]. Samadi Taheri, M.M., Hassani, H.R., and Ali Nezhad, S.M.: 'UWB printed slot antenna with Bluetooth and dual notch bands', IEEE Antennas Wirel. Propag. Lett., Vol.10 (2011) pp. 255-258.

[9]. Ojaroudi, M., and Ojaroudi, N.: 'Ultra-wideband small rectangular slot antenna with variable band-stop function’, IEEE Trans. Antennas Propag, Vol.62 (2014) No.1, pp. 490-494. 